Kairos. Journal of Philosophy \& Science 19, 2017

Center for the Philosophy of Sciences of Lisbon University

\title{
Probing Cognitive Enhancements of Social "Resonance" - Towards a Aesthetic Community of Sensing and Making Music Together
}

\author{
Alexander Gerner' ${ }^{1}(\mathrm{PhD})$ \\ CFCUL \\ alexandergerner@gmail.com
}

\begin{abstract}
In my general aim to probe a non-reductionist Philosophy of Cognitive Enhancement, considering social self-other relations and the epistemic 2PP in social syn-aesthetic tuning-ins, synchronisations and tuning-outs, this paper amplifies

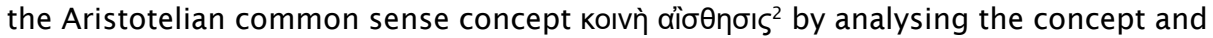
metaphor of "resonance" 3 in contemporary debates on $>$ resonance $<$ as acoustic and multimodal figure of thought. Resonance as shown in scientific models derived from acoustics will be applied to an aesthetic comunity of sensing and making music toge-
\end{abstract}

1 This paper was supported by an FCT grant on "Philosophy of Cognitive Enhancement" (SFRH/BPD/90360/2012).

2 Two notions, expressed in the following two questions, have to be distinguished when dealing with common sense in Aristotle, the second of which I will expand in this paper: "What does Aristotle designate with the phrase 'common sense'? What should we designate as the Aristotelian notion of common sense?" Gregoric, 2007, 207. These two notions of common sense in Aristotle explains to some extent the controversies that the Aristotelian understanding of common sense haunts us until today: "An attempt to summarize uncontroversial points concerning Aristotle's notion of the common sense yields a disappointingly short list. First, it is a perceptual power distinct from the five ordinary senses. Second, it is a perceptual power of a different type and order from the five senses. Third, it allows Aristotle to say that the five senses are not mutually independent capacities, but form a kind of unity. Fourth, it is closely connected with Aristotle's idea that the heart is the central sense organ. Fifth, it is in charge of certain functions that, in Aristotle's view, go beyond the five senses taken individually. Every further point or specification is likely to be controversial". Gregoric, 2007, 13.

3 This paper explores the preliminarily non-reductionist resonance-in-interaction concept further as exposed in Breyer and Gerner (2017), and extends their approach to inner-bodily and inter-corporal common sense, going into detail on the scientific metaphor of "resonance" and paralel concepts specifically in social psychology, besides introducing technically induced xeno-resonance. 
ther as explored in Alfred Schütz, as well as in social relations in social psychology. Finally, this paper puts resonance to test as well in technical atunements of social relations and closes with the necessary resistance to imposition of social resonance, introduced in this paper as xenoresonance.

DOI 10.1515/kjps-2017-0012

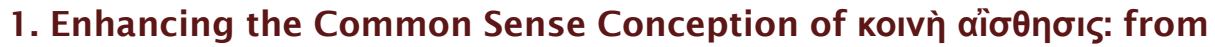
the Heartbeat of Rythmic Interoception to Social Resonance?

My general purpose is to probe a non-reductionist Philosophy of Cognitive Enhancement. I will consider social self-other relation and an approach to "common sensing" and making music together by social tuning-ins, synchronizations and tuning-outs. This means that the idea of enhancing common sense is located not only on the individual level of sensing and sense making but understood in a framework of collective human enhancement for cognitive, social enhancement. I explore these communal enhancement forms starting with an aesthesis-based concept of embodied common sense, intercorporeally extended by an Aristotelian notion of community in an excelent friendship of shared perceptions.

Aristotle's account of common sense is notably discussed under the term koine aisthesis ${ }^{4}$ still controversially ${ }^{5}$ debated today.

Nevertheless, I want to approach the complex idea of not only inner- but as well as inter-bodily common sense with the concept and metaphor of social resonance. Otabe ${ }^{6}$ rightly notes that already in Aristotle these two notions of common sense are given as a unity of cross-modal perception

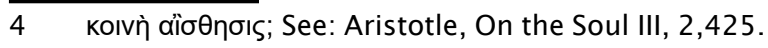

5 Gregoric $(2007,1-14)$ develops a more detailed overview of the debate koıvì đî̀ $\theta$ noıs in Aristotle that reaches beyond the scope of this paper: Some researchers see in Aristotle's common sense account a) a rudimentary theory of consciousness; b) a truncated concept of a universal faculty of perception c) including the feeling of time, d) including the capacity for imagination; e) including the ability for memory; f) including the ability for dreaming; g) the capacity of conscious perception that disappears when falling asleep h) the capacity of the joint activity of the five Aristotelian senses, i) the perception of the 'common sensibles'; j) the perception of the 'incidental sensibles'; k) the perception that we are perceiving; I) discrimination between the objects of different senses; $m$ ) understanding simultaneously different sense objects; $n$ ) perceiving that sense objects belong to one thing (integration); o) perceiving synaesthetically objects of one sense by another sense; $p$ ) to objectify perceptions, attributing objective reference to perceptual content.

Otabe, 2015, 37. see as well: Porter, 2010, 193-6. 
and joint power (koinê dynamis7) as well in an "inter"corporeal, basic intersubjective sense.

My amplification of inner-bodily aesthetics in common sense is due to the inclusion of a social co-aesthetic dimension of social rhythmic musicing and music making, including individually embodied Common Sense and syn $^{8}$-aesthetic intercorporal co-variants. Aristotle's embodied kovvi

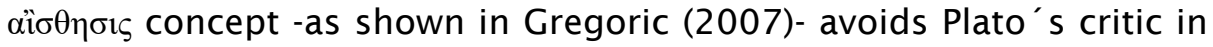
Theaetetus ${ }^{9}$, by grasping common ${ }^{10}$ features ( $\tau$ c̀ kotvó) and unity of sensibles $^{11}$ (De anima, III.2, 425a16) in perceptually coordinated and integrated Aisthesis rehearsals that -in my view- include social syn-aesthetic co-features as well. Apparently, we cannot follow Aristoles reduced account of the physiology of only five senses (sight, hearing, taste, smell, and the proximate sense of touch ${ }^{12}$ ) anymore today. Contemporary debates on humans and other species take more distinctive senses ${ }^{13}$ into account.

$7 \quad$ Aristotle, On Sleep and Dreams, 2,425 a30-31.

8 Sunaisthēsis in Aristotle, Nicomachean Ethics IX,9,1196b5-1172a15 does in itself not imply a community of modern self-conscious thinking selves but indicates that in the encounter of friends a "with-perception" shows up when Aristotle refers to friendship in common shared aisthetic experience inside an aesthetics of shared life in excellence with friends.

9 Gregoric showed the difference of Aristotle perceptual common-sense based view to Plato's position: "That is to say, what is required for Aristotle's project is a notion of the soul in which co-ordination of the senses does not involve thinking, but is achieved entirely at the level of perception. For this purpose, and in line with the basic premisses of his philosophy, Aristotle proposes a significantly different picture of the soul and its relation to the senses. (...) In Aristotle's theory, the senses are not integrated at the level of something that is the subject of both perceiving and thinking. Rather, the senses are integrated by the common sense. Thus integrated, co-ordination of the senses is achieved perceptually, and it can be attributed to non-rational animals". Gregoric, 2007, 6-7.

10 As Porter, 2013, 14, explains well: "Aristotle's point is general, (...) perception (aisthēsis) is wider than, and includes, ocular seeing. The idea that sound and colour are both common to aisthēsis points indirectly to Aristotle's theory of common sensibles, or koina aisthēta, which he develops in his psychological works. These are the sense objects that can be perceived through the different sense faculties commonly (for instance, movement, rest, number, shape, magnitude, sharpness, bluntness [these last two may be variations of shape], and - controversially - time)".

11 Aristotle, 2011, 60, II.6.18-20.

12 Aristotle, 2011, II 423b12-1 8, 21, distinguishes distance senses (vision and hearing) from immediate senses such as touch.

13 Besides the five senses mentioned by Aristotle, other senses are researched on today: thermoception, vestibular sense, proprioception, interoception (visceral senses, nociception, vestibular sense, the body schema) among others. 
Nevertheless the problem that Aristotle poses stays actual: what should a unified common sense concept of an intuitive "sixth" sense conceptually deliver to clarify different common aspects of all senses, such as perceiving common perceptibles, discriminating perceptible modalities, sense coordinations and integrations even in cross-modal ${ }^{14}$ and synaesthetic modalities and their intercorporal shared community of sensing? Don't we as human beings have an existential rhythmic inner sense of Life $^{15}$ in its interplay of resonant social tuning-ins within ourselves, with others and our environment? Aristotle does not treat this particular point in detail. Nevertheless, his reflections on the excellence of a good life in the social companionship of a few friends, get close to it. In the Nicomachean Ethics Aristotle follows this idea by applying an analogy of musical expertise ${ }^{16}$ and the awareness ${ }^{17}$ of the other proposing a common sense enhancement by social bonds of community and concurrently perceiving (Sunaisthēsis ${ }^{18}$ ) while living with friends in exellence ${ }^{19}$.

14 Recently in a preprint paper the crossmodal synchrony in a co-varying double motion of the senses of sight and sound for example in eye-saccade movement rythms and eardrum motion synchronisations was shown by Gruters et al., 2017. Kadosh et al. 2009 endorsed a disinhibition model of cross-modal neural conections for synaesthetic experience.

15 See Heller-Roazen (2007) on the existential reading of koiné aisthesis as inner sense ("inner touch") in between passive sensation, active perceptive awareness, sense of sensing as well as feeling of existence and sentience, that all animals are supposed to have in common.

16 "(...) for the good man in so far as he is good, delights in actions in accordance with excellence, and is disgusted by those flowing from badness, just as a musical expert takes pleasure in fine melodies and is distressed at worthless ones. Living in the company of good people may also provide a training in excellence, as Theognis says". Aristotle, Nicomachean Ethics, IX, 9, 1170 a8-10.

17 Aristotle, Nicomachean Ethics IX, 9, 1170a12-32.

18 Sunaisthēsis can not only be translated as "to perceive at the same time" (Aristotle, Nicomachean Ethics, 1170b4) as a pre-notion of syn-rhythmic consciousness, but as well as "with-perception" with others. For Aristotle "to perceive [aisthanesthai] that we perceive or think is to perceive that we exist" and a performative performative existential aesthetics of living "that one lives" (hoti zēi), because for Aristotle existence as well as life are "defined as perceiving or thinking", and therefore can be developed in a shared common sense of "with -perception" engaged with synchrony of feelings, perceptions, and sentience in a shared life in friendship. Cf. Porter 2013, 15: "For an interesting bridge to shared social perceptions, see sunaisthēsis at Eudemian Ethics 8.12.1245b24, used of shared social perceptions (among friends and more generally, by extension). More might be done with this extension to the public sphere of experiences (for the concept, see Porter 2010: e.g. 7, 193-6, 454)" Porter 2013, 15.

19 See: Aristotle, 2011 , Nicomachean Ethics, IX, 9,1170b4-19. 
Contemporary adaptations of Aristotle's account seem relevant for

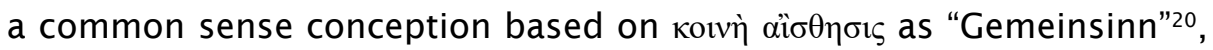
"unity of senses" 21 , and "Gemeingefühl"22 and its inter-corporeal extension in sharing (to koinonein) with others an existential community of living together (to syzen).

Noteworthy is the fact that Aristotle pinpoints the heart ${ }^{23}$ as the primary core of common sense. As counter-intuitive as this seems, it shall interest us here: The kinetic ${ }^{24}$ organ of the heart and its dynamic rhythm in contemporary research is described - not as located at the center of all senses, but as central to the interoceptive sense. Interoception deals with the perception of bodily sensations derived from physiological, visceral sensations such as pain, hunger, thirst, gut feeling, or heart rate that - according to Garfinkle et al. (2015)- is concerned explicitly with the sensing of internal bodily changes. Besides a restrictive meaning of interoception as viscero-sensory integration ${ }^{25}$ in a broader sense, it has been used to signify coaenesthesia ${ }^{26}$ and even has been conceived with the

20 For philosophical anthropology (Krueger 2000, 16;23) based on intuitive senses and sense-making, common sense as "Gemeinsinn" does not exhaust itself in mere intuitive perception, but- in order to act accordingly in a given situation- has to become able to deal with how to act in an ever changing and technologically influenced (biological) nature (bios), history, culture, individuating and socializing world: "Common sense \{Gemeinsinn\} is based on the interaction between the intake of the bodily senses, the mental senses and the judgement of the apperceived, from which the consequence derives to do something or to refrain from doing something, that is to draw conclusions by praxis (in praxi). Otherwise the convenient coordination of all situatively relevant aspects in the act of living life, its tuning-in together (Zusammenstimmen), would be doomed to failure". my translation.

21 An important position on the unity of senses can be found in Plessner's Aisthesiology called "Einheit der Sinne" (1923).

22 In the Aristotelian separation of the sense of touch and the common sensibles, Weber (1846) developed a notion of interoceptive bodily sensation without any external as "Cemeingefühl".

23 Cf. Gross, 1995. Cf. Aristotle, On Sleep And Sleeplessness, 1319 "for all sanguineous animals have a heart; and from this it is that both motion and the controlling sense-perception originate".

24 In Rose's $(1906,16)$ reading of Aristotle the kinesis in the central organ of the heart constitutes Aristotles concept of perception.

25 Critchley and Harrison, 2013.

26 Cf. Berrios on Gemeingefühl or coenhesthesia: "Gemeingefühl refers to the remaining corporal sensations once those associated with the skin (that is touch, temperature, pressure and location are seperated off. They constitute a heterogenous array such as pain and "objectless" sensations such as well-being, pleasure, fatigue, shudder, hunger, 
phenomenal ${ }^{27}$ experience of one's own body state. One exciting aspect of interoceptive awareness between first, second and third person access, is the capacity of detecting inter-bodily sensations of heartbeat rhythms and its accuracy. Heartbeat-phases and emotional arousal are interoceptively closely related to the function of aterial baroceptors ${ }^{28}$, located in the aortic arch and carotid sinuses to control blood pressure by a reflex in the brainstem called baroreflex. Phasic stimuli between heartbeat rythms and affective states ${ }^{29}$ - anxiety for example or fear and joy ${ }^{30}$ - enhance when rhythmic coordination of phasic heart activity and brain activity synchronically match. Today, we assume that the inner (interoception) and outer perception $^{31}$ (exteroception) are strongly crossmodally ${ }^{32}$ coordinated, so that phasic interrelation as well as sensory integration ${ }^{33}$ - another contemporary topic of common sense related to an Aristotelian conception - of inner bodily changes joint with outer perception, can influence general physical awareness.

In this context research on how people are accurate ${ }^{34}$ about one of their embodied pace-maker, the heart, in homeostatic monitoring and judging accurately on their inner bodily states becomes relevant. Professional musicians ${ }^{35}$ are more precise than non-professionals in their attention to monitor and detect rhythms, beats, and changes. Stock-traders ${ }^{36}$ seem to be more successful in risky decision-making if they have accurate "gut feeling" measured in this case in the accuracy of conscious heartbeat interoception. If common sense in this line of thought would be related

nausea, organic muscular feelings etc. ... This group were also called coenesthesia and some workers speculated that they provided the experiencing subject with his sense of existence". Berrios, 1982, 288.

27 Ceunen, et al., 2016.

28 Garfinkel et al., 2016.

29 Schandry, 1981. Affectivity and emotions in this sense can be seen as encompassing not only behavioral and experiential, but as well visceral changes.

30 Fuchs and Koch, 2014.

31 Aspell et al., 2013.

32 Herbert et al., 2012.

33 Suzuki et al., 2013.

34 Garfinkel et al., 2015.

35 Schirmer-Mokwa et al., 2015.

36 Kandasamy et al, 2016. 
to the first part of the Delphic order " $Г v \tilde{\omega} \theta$ ı oautóv," Know thyself, it could

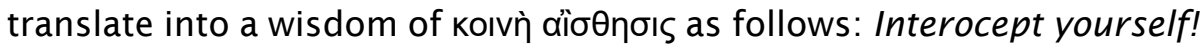

If and how far this insight extends to social enhancements, and how interoceptive abilities indicate a possible parallel training ability of affective and cognitive aspects of relating to others and have empathy ${ }^{37}$ with others, is another question to be followed.

For Stanghellini, in common sense the relation to others is central, and implies a twofold concept of common sense. First, koiné aisthesis, and secondly, koiné ennoia -that he translates with sensus communis. Koiné aisthesis - according to Stangellhini- includes sensory integration, pre-conceptual self-consciousness, ipseity, coenesthesis ${ }^{38}$, as well as supramodal perception to grasp objects across modal appearance, inter-corporeality, intuitive perception, social attunement by transfer of embodied schemata as intercorporality. His co-related concept of "Sensus Communis" includes bodily-based cognitive schema, types, rules of the game, database, koiné ennoia and social knowledge:

“(...) Aristotle's koiné aisthesis is not only the basis for the integrated perception of the physical world, but also for the meaningful perception of the other' behaviours in the social world. This concept is originally expressing both embodiment and attunement to the social world. The bodily and the social selves share the same experiential foundations. Koiné aisthesis is the basis for the phenomenon of emotional-affective attunement that is the prerequisite for the emergence of the social self and of intersubjectivity. It is the root of the learning of our shared world picture that we absorb during our psychological and cultural development

$37 \quad$ Grynberg and Pollatos, 2015.

38 The term Coenestesis was used in Christian Friedrich Hübners dissertatio inauguralis- supervised by Johann Christian Reil- as that which perceives its vital activities, registering the bare feeling of existence, the Gemeingefühl. Hübner defines "to feel" in the common sense faculty of the feeling sense as "alterations of the soul which are provoked by alterations of the body" Hübner cit. in: Heller-Roazen, 2007, 238. 
or Bildung. It is the non-propositional, emotional-affective prerequisite for the aquisition of comonsensical propositional knowledge (koiné ennoia or sensus communis)"39.

2. Alfred Schütz Approach on a Small Community of Sensing in "Making Music Together": Common Listening, Playing and Tuning-in

"Music is a meaningful context which is not bound to a conceptual scheme. Yet this meaningful context can be communicated: The process of communication between composer and listener normally requires an intermediary: an individual performer or a group of coperformers. Among all these participants there prevail social relations of a highly complicated structure“40.

In the following section I will attempt a first conceptual approximation with Alfred Schütz concept of making music together in which resonance as tuning-in relationships becomes necessary.

The phenomenologist Alfred Schütz (1951\{1976\}) in his essay "Making music together. A Study in social relationships" 41 recognizes pre-language kinds of Aisthesis -in rehearsal and performance of shared music making. These become the grounds of social mutual "tuning-in" 42 relationships, described in the example of a small number of musicians inside a near peripersonal ${ }^{43}$ space, in which they can act and play together. These joint music-making situations are -according to Schütz-non-semantic, pre-conceptual sense-making structures that I would call joint musicality.

From the outset, Schütz emphasized the independence of the quality of music-making and his social musical sensemaking from musical nota-

\footnotetext{
39 Stanghellini, 2004,121.

40 Schütz, 1976, 159.

41 Schütz, 1976.

42 Schütz, 1976, 162.

43 "near (peripersonal) space where objects can be acted on immediately and far (extrapersonal) space where objects are beyond immediate action" Griffiths and Tipper, 2012,1241 .
} 
tions, which for him are secondary means of expression and technical tools aiding the proper reproduction of a piece of music in a conventional ${ }^{44}$ language. For Schütz the social process of music is neither linked to a particular notational system, a score, or any any other group-specific semantic communication system nor is it dependent on the degree of professionalization of the music-making actors -musicing around a fire is equally valid as well musical rehearsals and performances of highly educated musicians. For Schütz the "mutual tuning-in relationship between the communicator and the addressee of the communication" 45 lies at the core of the music process. At the same time, these common tuning-in procedures are paradigmatic cases for researching social relationship in musical situations. Herby human beings share a common space-time located at such distance that they can engage directly in performing activities ${ }^{46}$ without needing the mediation of a third party, even that objects can be handled in between them and being able to be acted upon synchronously or in a turn-taking fashion. The music players engage in performing activities, which are integrated into the external world and thus take place in shared events of a lived ${ }^{47}$ community of space that unifies fluxes of phenomenal inner time of each of the players. Shared participation in different temporal dimensions lie at the core of the social relationship of the players, which are simultaneously experienced by the participants.

In this shared zone of space-time- for Schütz- the interaction from the epistemic point of view, that today we can name Second-Person Perspective is exemplified in a visual enactive sense by the notion of Cooley and his face-to-face $(\mathrm{F} 2 \mathrm{~F})^{48}$ relation. The direct F2F relation is a community of socially perceivable and shared space, experience or objects that implies the possibility of directly acting on intimate relationships and with joint

44 Schütz $(1976,166)$ develops a critical stance against merely representional meaning based interpretation schemata in sense-making contexts mediated via musical notations.

45 Schütz, 1976, 177

46 Lakens and Stel, 2011.

47 Schütz 1976, 177.

48 "(...) making music together is an event in outer time, presupposing also a face-toface relationship, that is, a community of space, and it is this dimension which unifies the fluxes of inner time and warrants their synchronization into a vivid present". Schutz, 1976, 177. 
gaze following in "joint attention" 49 . The F2F is opposed to larger groups, collectives, and collective bonding ${ }^{50}$, where a direct contact and possibility of acting or playing together has to be mediated. Bigger groups usually need third party coordination and orchestration (as a conductor for an orchestra) for installing or maintaining the coherence and coordination of the group's attention.

Schütz revisits several parallel theoretical models of his time to describe resonant tuning-in relationhips in "Making music together":

"As far as the question under scrutiny is concerned, the concrete researches of many sociologists and philosophers have aimed at certain forms of social intercourse which necessarily precede all communication. Wiese's "contact-situations", Scheler's perceptual theory of the alter ego, to a certain extent Cooley's concept of the face-toface relationship, Malinowski's interpretation of speech as originating within the situation determined by social interaction, Sartre's basic concept of "looking at the Other and being looked at by the Other" (le regard), all these are just a few examples of the endeavor to investigate what might be called the "mutual tuning-in relationship" upon which alone all communication is founded. It is precisely this mutual tuning-in relationship by which the "I" and the "Thou" are experienced by both participants as a "We" in vivid presence". (Schütz 1976, 161).

49 A concept to be developed in the future, as a social grounding of common sense derived from koine aisthesis, is "joint attention": "You may define joint attention, quite narrowly, as a particular kind of perceptual state (e.g., Peacocke, 2005), or you may think of it in terms of a type of bodily anchored mode of intersubjective engagement vis-à-vis a shared world (e.g., Hobson, 2002); you may take it that the ability to jointly attend to objects with others is present, at least in rudimentary form, in the great apes (e.g., Leavens $\&$ Racine, 2009), or you may argue that the kinds of cognitive capacities which have to be in place for this feat to be possible are uniquely human (e.g., Call \& Tomasello, 2005). (...)" Seemann, $2011,1$.

50 Pearce et al., 2016. 


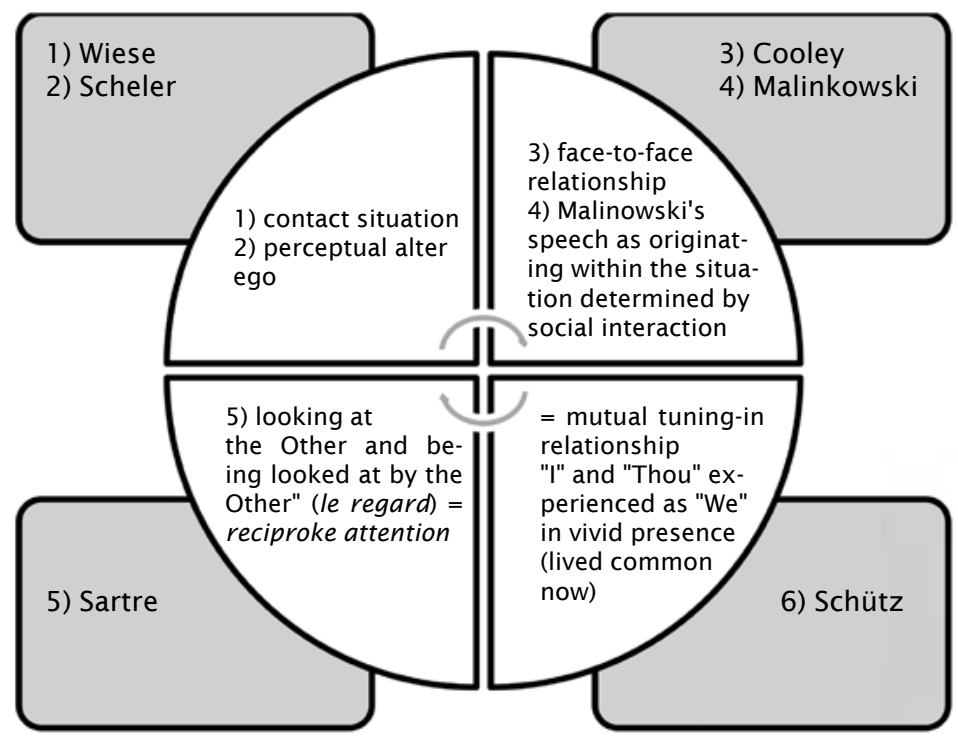

Three instants make up the Mutual tuning-in relationship as conceived by Alfred Schütz that I want to summerize as follows:

(1) Schütz conceives the mutual tuning-in relationship as a temporal participation of the other in internally experienced time of each player. As he notes, this is "established by the reciprocal sharing of the Other's flux of experiences in inner time" 51 that reigns the relations of the composer of music and its beholder ${ }^{52}$, as well as the listener and the music performer. Therefore the mutual tuning-in relation can be grasped only by shared immersion ${ }^{53}$ in the ongoing flux of the musical performance of the players involved ${ }^{54}$.

\section{Schütz 1976, 170. \\ 52 Schütz 1976, 171. \\ 53 Schütz 1976, 173.}

54 This adds up to the prosocial effect in the synchronicity of entrained performing (music) together as proposed by the reinforcement of cooperation model of Reddish and collegues:"Despite variance in expressions and contexts of collective music and dance performances, one common underlying factor found in most forms of collective music and dance is the matching of rhythmic behaviours amongst performers. Performers move their bodies or produce sound at the same frequency (frequency-locked synchrony) or phase (phase-locked synchrony) (Clayton et al 2004). Behavioural synchrony has been linked with greater social bonding and cooperation suggesting that such synchrony could be one 
(2) A face-to-face relationship shared in external-temporal space whereby Schütz emphasizes the body and movement component of this tuning-in onto a partner: a "sharing of the other's flux of experiences in inner time, this living through a vivid present in common" 55 . The necessary $2^{\text {nd }}$ Person "close face-to-face relation" (Ibid.) in the rehearsal of the "musical We" of a joint attentional musicality is limited to a handful number of direct interacting co-performers. A bigger group of musicians cannot be directly held in the field of a face-to-face encounter. According to Schütz a larger group of players can be indirectly coordinated via the mediator of a third party, a leading voice or chorister, a continuo player, a concertmaster, a tact-giver, or a conductor.

For Schütz the moment of sharing a live situation with the presence of bodies ${ }^{56}$, including their joint attentional gazes, movements and tool-handeling ergotic gestures, while performing together, is crucial.

(3) as a "we"

of the key mechanism behind collective music and dance's prosocial effect" Reddish et al.2013; see as well: Rennung and Göritz, 2016.

55 Schütz, 1976, 173.

56 "the Other's body and its movements can are interpreted as a field of expression of events within his inner life. Not everything that is interpreted by the partner as an expression of an event in the Other's inner-bodily life is meant for the Other to express - that is, to communicate to the partner - such an event. Facial expressions, gaze, posture, ways of handling tools and instruments, without communicative intent, are examples of such a situation. The process of communication proper is bound to an occurrence in the outer world, which has the structure of a series of events polythetically built up in space-time. (...) communication within the face-to- face relationship" Schütz 1976, 177-8.

57 Schütz 1976,177, by far conceptually anticipates social cognition research on the we-mode, however in how far this we mode is in need of a collective intentionality is to be clarified: cf. Galloti and Frith, 2013. If the constitution of the social relation, as in-between affectivity and Interaction, should presuppose a collective We-Intentionality stays doubtful with Bernhard Waldenfels: who asks " $(\ldots)$ if the $>\mathrm{Co}<\{>$ Mit $<\}$ of Co-subjects, the $>$ Inter $<$ of Intersubjectivity order the $>$ Between us $<$ is, in any case, something, that actually emerges from an intention".

58 Schütz in another text on music "Mozart and the Philosophers" explains his view on Intersubjectivity by analyzing the "We" in Mozarts opera Figaro, in which the Austrian composer establishes" (...) an intersubjective community, now between the various dramatis personae, is the secret of Mozart's powerful treatment of the ensembles, the third distinctive feature of his operas. To be sure, every dramatist places his characters in a community of space and time, and makes them share a common situation to which they react in a particular way as they act and react upon one another. But the dramatist can present their diversified actions and reactions only in succession, and therefore in isolation. To show them in simultaneity is the privilege of the musical drama. Yet Mozart does more: he uses 
The processual-enactive and simultaneous "experience of a living presence" (Ibid) constitute these three levels of socio-cultural musical resonance. About the text "Making Music together", Waldenfels suggests that social, linguistic and communication theories should be investigated, in response to (1) common musicality, (2) joint music making or music rehearsals, and (3) phenomena such as synaesthesia or synergy, to bring the corresponding theories closer together to the phenomenal reality. The research task is given in musical rehearsals in which still no intentional goals or fixed social roles are distributed between "maker" or "receiver" in an improvisational fashion. Waldenfels notes that each musician is tuned-in and listens in an in-between-mode in which each musician has "to play listening and listen playing" by a mutual engagement in the music making situation.

"Everyone hears itself in the other in the form of an original echo, that assimilates to a mirrowing in the gaze of the other. The inner polyphony does not appear as a special case but as the rule. As in an inner monologue someone speaks with himself as another equally a solist plays with himself as another. Different to the myth of the nymph Echo, that repeats after the other all that she hears, this strangeness does not come from outside, but from the middle of playing music"59.

We want to underline three conceptual moments that bring our idea of resonant interactions further with Waldenfels $(2010,166)$ :

a) Originary echo,

b) inner polyphony, and instead of a third entity, a we as in Schütz, he proposes

this specific device of the art form of opera in order to present in immediacy the intersubjective relations in which his characters are involved. In spite of their diversified reaction to the common situation, in spite of their individual characteristics, they act together, feel together, will together as a community, as a We. This does not mean, of course, that they act, feel, or will the same, or with equal intensity. On the contrary, ensembles such as the admired first Finale of Figaro clearly show many groupings of the personae involved, both in cooperation and in antagonism. Nevertheless, even in antagonism they are bound together in an intersubjective situation of a community, in a We". Schütz, 1976b, 198-99.

59 Waldenfels, 2010, 166, my translation. 
c) "the middle of playing music" as a performatively given intercorporal probing, before any pre-given we-intentionality. All three elements are important, if we reflect on social resonance in making music together. Hereby we should look at improvisatory, unperfected gestures ${ }^{60}$ or non-habitual movements and (faulty) polyphonic rehearsals in-between musicians, although not be restricted to them. The experience of "embodied movement" as being moved together in inner-personal time does not necessarily imply external synchronized movements, but as well occurs while the gesture of mere listening ${ }^{61}$ and not only by moving our bodies to music we listen to ${ }^{62}$. Synchronization in mutual tuning-in relationships can be found in contemporary evaluations of social research methods of cross- and multidisciplinary approaches to interpersonal synchrony, for example in social signal processing, computational neuroscience, developmental psychology and child psychiatry as Deleherche ${ }^{63}$ shows and as the feeling of an enacted togetherness ${ }^{64}$. In how far are synchrony of body-movement, postures and pre-semiotic gestures crucial for the origin of a community of sensing, the process by which independent rhythmical resonant bodies interact with each other?

\section{Resonance as Technical Metaphor for Scientific Models}

In this section I will introduce resonance as a technical metaphor for scientific models derived from acoustics to social psychology and within technological enhancements of self-other relations.

In inner-musical resonance, a tone in an instrument not only causes the same frequency to resonate with it- as we can measure in the original tonebut also overtones and undertones are activated when the strings begin to

60 Mazzola, $2011,243-244$.

61 Peters, 2010.

62 What should be taken into consideration is the evolutionary stance that listening to sound has for the development of tools and their hominid use: See: Killin, 2016, 432.

63 "Rapport building, the smoothness of a social encounter and cooperation efficiency are closely linked to the ability to synchronize with a partner. The close link between synchrony and interaction quality bears promising perspectives for researchers building social interfaces, robots or embodied conversational agents" Deleherche et al 2012,1; cf. as well Breyer 2015,51.

64 Lakens and Stel, 2011. 
vibrate and sound without direct interference by the player. These are resonance effects of the wood of a (violin) body set in motion. "Sonar" refers to an acoustic oscillation; the "re" indicates a directional determination, namely, an echo or a counter-swing. The prefix "re" means that a vibration or an acoustic phenomenon already exists. This pre-existence of a sonar, before any actual cooperation or counter-oscillation of resonance starts, binds the resonance from the beginning into a preexisting connection and interaction, which, even in its resonance, requires a body to do so, as a counter-balance of the "sonor" as given. Other forms would be a coupling of dynamic systems and system states. Beyond these physical phenomena, resonance is fundamental at the level of complex social interaction between living organisms, in our example musically endowed persons and their vibrant environment. Resonance in making music together is more than entrainment and coordination of vibrations of a system $X$ via dynamic couplings in another system $Y$ over individual resonant frequencies, phases or vibrations. Resonance plays a role as a quantifiable mechanical phenomenon of homogeneous transmission: adaptation, matching of vibration, oscillation, and rhythms between physical or mechanical bodies, or the couplings ${ }^{65}$ of dynamic systems and system states. In relation

65 In describing the specific aisthesiology of the embodied sense of listening (Gehör) dependent on body postures, the fitting of awareness of tones, sounds and sound combinations in the physical attitude, (Plessner 1923,237) the philosophical anthropologist Helmuth Plessner notes that the difference between the atomistic physicalist interpretation of a reduced resonance theory in Helmholz (1896) of accoustic stimuli and their transformation into sensations via pooling, merging and coupling -in which sounds and tones have to be able to be hacked into parts, is opposed to Ewald's (1892) position, of the capacity of the act of listening as a perception of gestalts in which the swinging together of the resonant tones and sounds in each accoustic stimulus creates not only single waves, that have modulations according to their pitch and tone, but a joint stimulation as physical gestalts in the sense of Köhler (1924), that are transmitted on the nervous system, and from which the act of listening as a whole should start to be investigated and not from the atomistic level of parts. In this context it seems important to revisit the psychologism controversy at the turn of the 20 century between physiology, psychology and philosophy within an interdisciplinary shift from acoustic theories and tone psychology, to social psychological applications in which the divergence between Helmholtz, the teacher of Wundt and the tradition of apperception, and Stumpf, professor of Husserl and Gestalt psychology, would have to be disentangled by using the concept and metaphor of 'resonance.' I suspect that the seemingly unbridgeable positions of the psychologism debate are haunting us till today, making interdisciplinary approaches between empirical-quantitative and phenomenal- qualitative approaches challenging to achieve. This debate exceeds the scope of this paper and will be developed in an upcoming research on interdisciplinary controversies on tone experience, hearing physiology, accoustic sound and resonance. 
to its history of ideas, resonance models are usually" (...) transmission models, which function according to the logic of the resonant string" 66 . There is a "sympathetic resonance" between two matched strings of one Instrument that always shows "a margin of inaccuracy" 67 . Nevertheless, this idea of pre-existence of a sonar might lead us to the assumption that resonance in interaction, would be unable to constitute anything new. On the contrary to this view, resonance is more than a mere visual reflex or an acoustic echo, a mere doubling phenomena, or adding up of energy in a system, which would differ only by degrees of intensity or quantity from the initiating event. It is important to clarify that the proposed concept of resonance is conceived as a two-way resonance, if not a genuine interaction- including underdetermined and inaccurate margin of resonant deviation- cannot take place. Thus, resonance becomes fundamental at the level of complex social interaction and aesthetic common inter-bodily attentionality between living organisms and their environment. Resonance in this sense implies necessarily the capacity of the interacting players to stop, halt and suspend resonance by a syncope ${ }^{68}$.

\subsection{Resonance as Technical Metaphor for Scientific Models in Acoustics}

Resonance is for many years a favorite metaphor in many disciplines. However, a detailed examination of 'resonance' as a source area for a future systematic philosophical interdisciplinary study on "resonance" as metaphor and operative concept history of science and philosophy such as in acoustics, aesthetics, physics, music studies as well as biology, social psychology, social phenomenology, and sociology, is still a desiderata of research. Nowadays, resonance concepts in joint interaction are often handled by other designations, such as rhythmic regulations of per-

66 Welsh, 2009, 105.

67 See: Breyer and Gerner, 2017, 34.

68 Medical Syncope is characterized by a rapid onset, short duration, and spontaneous recovery often caused by global cerebral hypoperfusion (that is: blood lack in the brain) resulting mostly from hypotension (that is: low blood pressure), a passing out, fainting or loosing consciousness. In listening -for Nancy- selves are accessed as a resonance of a return: "(...) listening is passing over to the register of presence to self, it being understood that the "self" is precisely nothing available (substantial or subsistent) to which one can be "present", but precisely the resonance of a return [renvoi]". Nancy, 2008. 
formance, maintenance or development and differentiation of sociality. These neigbouring concepts are present in different disciplinary fields on diverse levels of investigation (such as tuning-in relations, attunement ${ }^{69}$, entrainment ${ }^{70}$, interpersonal synchrony ${ }^{71}$, or synrythmic regulations-that we will treat below). Even in the philosophy of biology ${ }^{72}$ resonance has been conceived. The metaphor and concept of resonance has especially become prominent in approaches of social interaction, in sociology ${ }^{73}$, social phenomenology and social and developmental psychology. Important in my view would be to combine these debates on the metaphor and model of resonance derived from acoustics, and combine them with other core forms of human social interaction and social aesthetics, such as musicking, joint musicality and music-making of musicians.

The concept of resonance awakens different theoretical models and associations in the history and philosophy of science. For instance, Chlad-

69 According to Ratcliffe $(2008 ; 2013 ; 2015)$ it seems of advantage not to speak of moods- as does Heidegger- when having in mind "existential feelings", because one basic weakness of Heidegger's "mood" concept is that it does not take into account and does not address the specific role played by the body in experience. Close to existential feelings comes the concept of "Befindlichkeit" or "Grundstimmung", basic attunement that for Heidegger is one of three inextricable ingredients of Care (Sorge) besides attuned understanding (Verstehen) and discourse (Rede).

70 Bernieri et al., 1988; see as well: Clayton et al.2004; Clayton, 2012; Geeves, et al., 2014; Doffman, 2009.

71 Paladino et al.,2010.

72 Bailly and Longo $(2011,255)$ develop the concept of "Bio-resonance" as destabilization of organisation on each level (cell/organisms/species) of singular living entities (biolons). They underline differences of deterministic and randomness conceptions of resonance not just of destabilisation and growth of entropy- a debate that exceeds the scope of this paper- but as well integration and regulation in singular living entities.

73 In a recent account, the Hegelian sociologist Hartmut Rosa (2016) states that the human being is not only able to achieve and live by language, reason, affects, but basically should be redescribed as an entity capable and open to resonance, a "resonanzfähiges Wesen" (Rosa 2016, 68). Rosa is mainly preoccupied with the societal impact of variability and changeability of social and societal state of affairs of resonance. He distinguishes three levels of resonance:

I) Existential social resonance sensibilities as horizontal relations in between people a) love, b) friendship, c) politics, either short resonance experiences or permanent resonance relations (resonant axises)

II) social resonance relationships as diagonal resonance to d) material thing world (work, "Bildung")

III) world relations, the vertical dimension as e) resonant, f) estrangement (Verfremdung) g) change. 
ni's (1 802) sound-figures $^{74}$ had installed an analogy and a difference between modalities of visibility and audibility in rendering acoustic bodily phenomena visible, in which the acoustic vibration of elastic bodies, introduces a different cross-modality, such as visuospatial diagrams of acoustics creating intermodal figures of sound.

As the history of science shows, knowledge has been derived by the substitution of musical cosmology metaphors by physical models such as of acoustics: Plato's cosmological music concept in which simple ratios of primal musical intervals prevail - the octave (2:1) the perfect fifth (3.2) or a perfect fourth (4:3)- show us an educational and musical harmony model that today seems one-sided, merely adaptive to a musical master structure, implying a symphonic ${ }^{75}$ resonance founding metaphor (Blumenberg), in which music, through the sensations of the individual soul of the pupil, coincides with the virtue of the "Logos". Plato does not think resonance as mutual social turn-taking in interpersonal relations and communication, but as a unidirectional affair, for example of the pupil that entrains to a pre-given harmonic order, onto his master's "soul". In a very elaborate cosmology, the "Harmonices Mundi"76 (1619), Kepler"7 attempts to use harmonious relations to explain cosmic organizations, including the organization of the collected data at the occurring maxima and minima of angular movements of different planets. The stability of equilibrium positions of mechanical systems is an old question and can be traced back to the 17th century. Shortly after the publication of the Principia Mathematica ${ }^{78}$ (1687) Newton gave a mathematically accurate description of the propagation of sound through the air, which marks the beginning of a new tradition in the mathematical study of music, that of acoustics. For Newton, the Pythagorean spherical music metaphor had to be substituted by a more accurate model to be followed: gravity. At the time, one of the problems associated with equilibriums of bodies, were

\footnotetext{
74 Chladni, 1809.
}

75 Plato, in the Sophist, proceeds from the metaphor of the symphonic sounding -together of concepts which harmonize with each other harmoniously or, on the contrary, do not belong together: Cf. Plato Sophistes 253bc cit. in: Arnold, 1998, 61.

76 Kepler, 1619.

77 See: Wardhaugh, 2008, 413.

78 Newton, 1687. 
the questions on the stability of the solar system and of heavenly bodies that astronomers and mathematicians investigated under the name of the $\mathrm{n}$-body problem. This issue was challenging to handle and for a long time did not reveal a precise or uniformly defined concept of stability ${ }^{79}$ of motion. Since Poincaré (1892/1893/1899), we understand the importance of gravitational resonance, or "path resonance", which originates in a "sympathetic resonance" from a resonance pole and a "disturbing resonance", and as such describes a critical nonlinear interaction on deterministic unpredictability at a level of organization, e.g., a planetary system.

Another example of the rich history of the metaphor and concept of resonance is given in electrophysics: For radio transmission the "electromagnetic resonance" between a transmitter circuit and a receiver circuit is a prerequisite: by this insight, Heinrich Hertz had augmented the scope of "resonance" that originated from acoustic and since then plays an important role as an "insightful model of Electrophysics"80.

\subsection{Resonance in Social Psychology: The Enhancement of Socially Bonding Selves}

Human selves can be said to be socially oriented from birth, as described by Meltzoff \& More neonate imitation studies ${ }^{81}$. In the development of social relations, it is psychologically relevant that infants can acoustically emit non-vegetative sound signals, cooing sounds, as first vocalizations in the first month of life. These vocants - squeals, growls, vowel-like sounds- or protophones ${ }^{82}$, may initially arise randomly, but in

\footnotetext{
79 Lyapunov, 1892.

80 "For the transmission process of the radio, the electromagnetic resonance between the transmitter circuit and the receiver circuit is a prerequisite: the technical apparatus of the radio receiver functions as a resonator, which is tuned to the emitted frequency and is stimulated by this. The fact that the transmission between resonant circuits is described with the concept of resonance goes back to Heinrich Hertz, who had observed how sparks were spiking between the diapole (the open resonant circuit) and a nearby receiving circuit (the resonator) This seemingly non-contact transmission process retrieved an analogy from acoustics: Just as the propagation of the sound can be detected by means of tuning forks, it had to be the case with the behavioral effects of electromagnetic waves on oscillation circuits. Thus Hertz had raised resonance originated from acoustic to an insightful model of Electrophysics". Lichau, 2009,12, my translation.
}

81 Melzoff and Moore, 1977.

82 "Protophones, infant vocalizations that are neither vegetative, fixed signals, nor effortful grunts, are deemed precursors to speech for at least three reasons: (1) they can be 
later months become babbling and shared attentional resonances with the caring others. As this happens, babies respond to or initiate "proto-conversations"83, which can be described as "quasi-resonant nuclei of the Phonation stage $<(0-1$ month)" 84 . These first vocalisations of newborns are said to be a pre-syntactic functional flexibility of affect expression and by that in some recent models are located at the center of language evolution ${ }^{85}$. Musicing has been coceived as crucial factor in child care for strengthening the belonging to a group, investigated upon as "vocal grooming "86. Trevarthen ${ }^{87}$ calls the capacity of an infant to respond to communicative social interactions of its parents, a primary intersubjectivity as related to postnatal "synrythmic regulations" of mother-child emotional movements. After amphoteronomic regulations, in which an embryo or fetus is dependent physiologically via the umbilical cord on the mother's direct and immediate embodied support, synrythmic regulations of mother-child engagements and emotional attunements explore and probe postnatal encounters, exchange of affects, social bonding and cooperation. For Trevarthen key transformations linked to musicality ${ }^{88}$ and intersynchrony for a cultural experience in the first two years of human child development include intimate and mutual reciprocal interpersonal exchange, and confirmation of expressed interests and feelings as well as "Proto-conversational Narratives". Trevarthen refers to "proto-conversations" of mother and child, as described by Bateson ${ }^{89}$ in

produced spontaneously and endogenously (without any external stimuli), (2) they bear the property of functional flexibility, just as language does (...), and (3) they can be used flexibly in vocal interaction to respond to or initiate protoconversation (...). Each of the three infrastructural properties are foundational building blocks for language emergence (Oller et al., 2016)". Jhang and Oller, 2017.

83 Bigelow and Power, 2014.

84 Oller, 1980.

85 Oller et al. 2013,6318 , report on functional flexibility of positive, negative and neutral use of early pre-syntactic vocalizations, protophones, different from non-speech like affective fixedness of crys (negative) and laughs (positive) in the first 3-4 months. As well in primates we can find similar forms of flexible functionality of vocal behavior, as in Bonobos: See: Clay et al. 2015.

86 See: Dunbar, 1993; 1996; Cf. Fitch, 2006,13.

87 Trevarthen, 1979; 2001.

88 Trevarthen 2009; 2011; $2011 \mathrm{~b} ; 2006$.

89 Bateson, 1979. 
the 1970 's, as well as Stern ${ }^{90}$ NY studies on "regulation of social contact between a mother and her three and half-year-old twins". Stern's studies underlined the importance of rhythmic coordination of behaviors perceived by common-sensical communities of cross-modal social co-sight, co-touch, and resonant sound, as well as social affect attunement ${ }^{91}$, which prepared Trevathens studies of the late $60^{\prime}$ 's at the Cognitive Studies at Harvard as the starting point of a description of a "primary intersubjectivity" 92 based on "intersynchrony" 93 . From inter-synchronicity Trevarthen lead efforts to explain proto-conversational narratives. Other fields he saw as important to understand synchronicity in interaction were person-person games. In a developmental perspective, these interpersonal games lead to person-person-object games and manipulative play, which later on would help to show off strangers in fear and leads - according to his theory- to stronger forms of intersubjectivity, for example in common cooperative tasks, proto-language and immediate peer mimicking ${ }^{94}$ (imitation), organized rythmically by a time-lag of co-actions. There are several indicators for the importance of resonant rhythms and action repetition and resonant variations in between mother and child; one is what Trevarthen calls the

"innate capacity to partake in shared interest of the baby towards her mother's regard, to a mother's direct gaze eye-to -eye so that infants can be led to follow shift of gaze to the side "as long as they see the movement of the pupils" (Farroni ${ }^{95}$ et al 2004; Trevarthen 2011 , 83). It seems we are capable of an eye detector specialized to the "rhythm of movement": "Human eyes are specially communicative- we

90 Stern, 1971; 1974.

91 Stern,1985. "Stern's detailed descriptive accounts of "affect attunement" (Stern 1995(!)) are relevant in just this context. Before words intercede, we relate to others in and through movement and in notably affective as well as effective ways. Our social lives are indeed rooted in a dynamic intercorporeality that is kinesthetically and affectively resonant through and through". Sheets-Johnstone 2011, 515.

92 Trevarthen, 2011,86.

93 Condon and Sander, 1974.

94 Trevarthen, 201 1, 89-90. See as well: van Baaren et al, 2004.

95 Farroni et al., 2004. 
are the only primate to possess a white sclera ${ }^{96}$, which, with almond shaped opening between the lids and the black pupils, makes more visible not only the conjugate orientation of the eyes in the head in face confrontation but also the rhythm and patterns of the restless eye saccades, which carry information about motivation, changing interest and likes and dislikes"97.

Interpersonal coordination is not only restricted to interpersonal behavior and its behavioral matching (mimicry)- involving a time-lag of two interacting agents- and interpersonal synchrony ${ }^{98}$, but as well underpinned by affective ${ }^{99}$ resonances and joint attention ${ }^{100}$ as described in the above quote. Thus our concept of common sense can be defined by what we are affected by and that "Me" and "You" jointly attend to something in common, rather than sharing any already pre-decided intention of planned action and mental states, that attune our interpersonal interactions, binds "you" to "me", and renders exits of synchrony, syncopes, possible.

An alternative to the concept of vocal, sound-based, preverbal resonances, the idea of system function, given in interactional coordination

96 The morphological human specificity white sclera, in opposition to dark sclera in big apes prepares human eyes physiogically to become specialists in joint attention; see: Kobayashi and Koshima, 2001. Tomasello et al. 2007 in his "The coorperative eye hypothesis", explores this human possibility to follow eye-direction and "advertise" the eye direction for others" (Tomasello 2014, 77). According to Tomasello this means that the white sclera and joint attention capacities are evolutionary morpho-physiological enhancements for stronger resonance for cooperation instead only competitive resonance: "For humans to have evolved conspicuous cues of gaze directions, there must have been some advantage to the individual to "advertise" her eye direction for others. This suggests predominantly cooperative situations in which the individual may rely on others using this information collaboratively or helpfully, not competitively or exploitively". Tomasello $2014,78$.

97 Trevarthen $2011,83$.

98 Bernieri and Rosenthal, 1991.

99 Páez et al., 2015.

100 Wolf et al., 2016. "Joint attention was sufficient to encourage social closeness with an interaction partner, which suggests that any activities which encourage attending to the same point in space could have some influence on how connected coactors feel about one another". This research attenuates the Shared collective Intentionality theory of Tomasello et al (2005) towards the primary importance of joint attention over shared goals and common intentions. 
and interpersonal synchronicity ${ }^{101}$, specifically in frameworks of non-verbal, embodied and emergent ${ }^{102}$ phenomena, such as in rapport/ synchrony interplay ${ }^{103}$ has been developed, as a model for enhancements of prosocial behavior ${ }^{104}$ by synchronic coordinations and interactions ${ }^{105}$. In these approaches ideally not only a) facial affect expression are taken into account, but b) as well gestures and c) body-postures and d) body movement rhythms, that all could be handled in my view in an encompassing concept of interbodily resonances. Resonance as well fosters the overcoming of self-other boundaries or blurring of the self-other barrier. As a result, self-other fusion ${ }^{106}$ is either enhanced or social, and individual aesthetics of common sense can be remapped ${ }^{107}$ by shared multi-sensory experiences. The blurring of the self-other barrier can, however, have adverse outcomes: social resonance enhancements can foster destructive ${ }^{108}$ obedience to a doubtful social, aesthetic common.

\subsubsection{Notes on Enhancing Intimate and Social Atunements}

If the primary common sense as directly-engaging-with-others (sensing, playing with others, musicking with others, sharing facial, vocal and attentional gaze behavior, being silent or non-active and sharing peripersonal space with others), is disturbed, the main way to compensatate -it seemsis given in inference or rule-based behavioral strategies, to cope with the lack or disturbance of direct interembodiment of direct engagement ${ }^{109}$. In this context it is -as well- possible to distinguish social resonance from Folk psychology (FP) approaches, in the sense that social resonance is

101 Condon and Ogston, 1966.

102 Ramseyer and Tschacher, 2011.

103 Nelson et al., 2014.

104 Cirelli et al., 2014.

105 De Jaegher et al., 2017.

106 Mazzurega et al. 2011.

107 "(...) shared multisensory experiences represent one key way to overcome the boundaries between self and others, as evidenced by changes in somatosensory processing of tactile stimuli on one's own face when concurrently viewing another person's face being touched". Cardini, et al., 2013, 630.

108 Wiltermuth, S., 2011.

109 "As we can see from Grandin's report, the bodily sensus communis cannot be substituted by explicit inference or rule-based knowledge about others' behaviour". Fuchs, 2015,198 . 
below propositional level, and implies reciprocal ${ }^{110} 2 \mathrm{PP}$ direct engagement with one another ${ }^{11}$, and is not based, in opposition to FP, only on expertise ${ }^{112}$, judgement of the other and their belived or conceived mental states. This distinction is relevant in psychological and psychiatric disorders, such as in schizophrenia ${ }^{113}$, or children with autism ${ }^{114}$ with difficulties in interpersonal relations, comunication and self-awareness, and might partially be enhanced by technical ${ }^{115}$ means. Resonance in this context becomes an operative concept in the moment it deals with "what it feels like to relate to people, that is, to share with, to learn from, to compete, to trust, to envy, to love and hate, to need, to lose and to do and feel all kinds of other things with people"116.

110 The 2PP- as Przyrembel $(2014,20-52)$ explains is not necessarily bound to interaction as proposed by Schilbach (2010) and Schilbach et al (2013) refering to networks and conectivities of "mere motor resonance" mechanisms. The 2PP is either asymetrical- in which the epistemic subject relates one-sidedly to the mental states of another person, or symmetrical in which at least two persons relate reciprocally to each other and are at the same time both epistemic subject as well as epistemic object for the other epistemic subject. Przyrembel 2014, 110.

111 Rosa, 2016, 298, distinguishes resonance from mere entrained echos as a relation of reciprocal response: "It presupposes that both sides speak with their own voice (...). Resonance implies a moment of constitutive inavailability". My translation of the german original text.

112 For Ratcliffe, 2007, 229 - as we actually do not always think and behave in social situations correspondingly to what we say or think and do- we should distinguish three categories: "1. Non-conceptual, practical social abilities. 2. Conceptual social abilities. 3. Ability to reflect verbally on 1 and/or 2". For Ratcliffe Folk Psychology (FP) -usually researched on in false belief tasks- is defined as a special case of social commonsense interpreted from an appropriate standpoint of expertise and not as a basic rule of social interaction such as developed in Theory-Theory (TT) and Simulation-theory (ST) of understanding other minds. See as well the critic on ST and TT views that should be overcome by Gallagher and Hutto, 2008.

\section{Varlet et al., 2012.}

114 Hobson that studied autism for long, for example, refers to DuBois dialogic syntax and resonance model on the dialogic level of linguistic-syntactic verbal interaction. Dialogic resonance refers to discourse patterns that arise when participants in conversation construct their utterances by selectively reproducing aspects of the linguistic structure of an utterance produced in the immediately prior discourse". Hobson, 2012, 2720. Resonance as a central concept of the model of Dialogic syntax is defined as the catalytic activation of affinities across successive utterances. See: Du Bois, 2007; 2014.

115 Autistic children for example relate better to robots than humans in robot-enhanced therapies. See: Peca, et al, 2016.

116 Hobsen, 2007, 44. 


\subsubsection{Brief Note on Techno-pharmacological Enhancements of Intimate Social Resonances}

The question put forward in a medical strategy of enhancement of wellbeing of social relations is, the following: Can we enhance (defective) intimate relations, and how do technological devices be of help in this? Is it feasible in ethical and epsitemic terms to enhance intimate relations for example by means of hormon-based pharmaceuticals? The breakdown of social synchronicity in coordinated body movements in dyads ${ }^{117}$ due to marital dissatisfaction has as well been exemplified in Julien et al. ${ }^{118}$. Should we therefore intervene in social intimate resonance relations and alter -for example- relations of married couples by hormon-based ${ }^{119}$ pharmacology? Resonance, as we have debated before, is the complex process of swing and counterswing in bodily intercorporal interaction between synchronicity, asynchronicity, entrainment and syncope or exit ${ }^{120}$ from unwished resonances and social attunments.

Thus, the bodily bond of joint rhythms of sensing leads us to the question if we can enhance intimate relationships for instance by the application of effective pharmaceutics based on bonding hormons for attachment and maintenance of intimate relationships or if desired their break up?

Sould we enhance (a) hormon- based attunement ${ }^{121}$ and falling in love, (b) maintaining synchrony or maintaining love or even (c) exiting syn-

117 Tschacher et al., 2014.

118 Julien et al., 2000; Fitzpatrick et al. 2016.

119 Wudarczyk et al., 2013.

120 "In many important interactions, such as therapy, marriage and parent-infant communication, it is the ability to exit and then re-enter synchrony that is thought to build strong relationship". Dahan et al., 2016.

121 for a call of scientific preocupation with transformation of intimate relations by technologically induced affect-attunements: see Earp and Savulesco, 2017. These authors self-critically disclaim the ambivalences of the project of enhancing intimate relations pharmacologically by pointing to the complexity of the levels envolved between hormon-level and long-lasting bons and relationships such as love-called "higher level experiences. For Savalescu\& Sandberg (2008) a so called "Neuroenhancement of Love and Marriage" examines the "imminent possibilities of biological manipulation of lust, attraction and attachment, so called 'neuroenhancement of love'". They hereby reduce love to its initial stage. That's why their 2008 approach should be called instead a (neuro-) enhancement account of falling in Love. Do we have the moral obligation to enhance fading emotions or disturbed relationships for example if common children in couples are involved? The normative stance of the obligation of having to take love drugs in relation to the responsibility 
chrony of intimate relationships if not desired anymore? Are application of hormones, neurotransmitters, pharmaceuticals or even electroceuticals ${ }^{122}$ effective?

We briefly and critically follow these question scrutinizing the manipulation, control and regulation of hormone-based emotional bonds, in particular when associated with social biochemistry and neuroscientific brain processes, underlying love (affection, infatuation, addiction, appetite behavior, attraction, mating/ selection/pair-bonding ${ }^{123}$ empathy, risk-taking, friendliness, acceptance, appreciation.) by introducing the debate on oxytocin: Oxytocin -besides Vassopressin and Dopamine- is one prominent candidate to cause and eventually enhance bonding behaviour in our body-brain system as several studies show Oxytocin's involvement in social intimate relationships and also in the attenuation of stressful social interactions. Oxytocin is said to suppress cortisol and subjective responses to psychological stress ${ }^{124}$, enhancing encoding of positive ${ }^{125}$ social memories or suppress (traumatic) memories ${ }^{126}$ as well as intentions and modulation of human cognition and fear ${ }^{127}$. Oxytocin -especially if applied in a intranasal way- has been shown to influence prosocial pair bonding behavior in non-human mammals, enhance trust ${ }^{128}$ in humans as well as gazes towards human faces and specifically to eye regions ${ }^{129}$, and even was proposed to enhance "mind-reading" abilities measured by a "reading the Mind in the Eyes" test ${ }^{130}$, which- however- has been experimentally refuted in a replication study ${ }^{131}$, that as well found that individuals with lower emotional empathy showed a stronger oxytocin-induced

of parents to their children to officially "save their marriage" developed by Earp et al. (2012) seems rather doubtful in terms of individual liberty and autonomy.

122 Famm et al, 2013.

123 Young and Alexander, 2012.

124 Heinrich et al. 2003.

125 Guastella et al. 2008.

126 Heinrich et al., 2004.

127 Kirsch, P. et al., 2005.

128 Kosfeld et al. 2005.

129 Guastella et al. 2008.

130 Domes et al., 2007.

131 Radke and Bruijn, 2015. 
improvement. Nevertheless, it seems problematic to not only propose a science $^{132}$ of intimate relationships but, moreover, a merely bio-technologically based techno-science approach to enhancement of social relations on the biochemical hormonal level, as this opens up the future of common sense for speculations about manipulations due to contemporary techno-scientific development of neuroceuticals ${ }^{133}$. To delete or erase unwished side effects of our complex make-up as human beings, in their failures and weaknesses, such as in the quest to remedy deviating social behavior is debated today under the label of moral (neuro-) enhancement and should be very critically assessed ${ }^{134}$. Can we define any rule about what kind of love relations or dysfunctional intimate relationships we should intervene upon, medically, pharmaceutically or by other technical means, such as by education or even self-formation? Does this techno-scientific perspective of enhancement of intimate relations on a pre-personal level foster or diminish common sense as Aristotle defined it?

\subsection{Conclusion: Xenoresonance as Directly Induced Comunity of Sensing by Technology?}

Should we be enabled to extend our bodily 1 PP perspectives and rythms in relation to the world and others in a community of sensing e.g. to switch seeing from my and from your visual position and thus adopting a xeno-rhythm for an technologically "enhanced" 1 st and 2nd Person (selfother) perspective? The possibility of jointly attending in mutuality, a autonomous Turn-taking ${ }^{135}$ in resonance, bi- or multidirectional change by starting, interfering or interrupting resonances is relevant in this sense as opposed to xenoresonance. Xeno-resonances deal with unidirectional entrainments on a pregiven or stabilized rhythm by one of the commu-

132 Fletcher, et al. 2013.

133 Wasserman and Liao, 2008.

134 For a critic on the limits of a biological reductionist moral enhancement proposal see: Wiseman, 2015.

135 Melzoff and colleagues note that change of communicational roles or "mutual turn-taking" as reciprocal resonance in interaction in attentional gaze-following of infants with robots is important, besides the robots engagement in (simulated) socially intelligent behavior- artificially inducing a belief of agency - of being other of resonant action- on the artificial agent, the importance of the human motivation to follow the robot's gaze, and in which the "robot's humanoid appearance alone was not sufficient to cause gaze following" Melzoff, 2010, 971. 
nicators/ sonance sources, imposed on the other. Xeno-resonance deals with altered selves as directly induced by technology as in a), proposed future medical treatment of paralysis in which interrupted, innerbodily resonances between nervous and motor-system are envisioned to be restored with brain implants by brain-spine-interfaces that have already been tested in monkeys ${ }^{136}$. Another example of xenoresonance would be b) direct brain-to-brain ${ }^{137}$ interfaces, for instance, when "l" become "we"138. These interfaces can be interpreted as directed or imposed resonances that clearly put forward ethical issues, such as "brain privacy"139: Are we experiencing a suspension of resonance or a new category of technologically induced resonance in which the "sound-source" takes over and entrains onto the receiving body a disciplinary regime of "slave-resonance" controlled by an uncontrollable other.

In this context, we have to consider another point: Affective resonances are distinguished from automatic co-affectivity of unwillfull contagious emotional experience \{Gefühlsansteckung $\}^{140}$. Gefühlsansteckung is a special case of feeling-oneness in a heteropathic form of temporary indistinguishable unity of selves: its psychopathic, or better xeno-resonant form of "affective absorption," can lead to loss of autonomy, self or induce personality alterations ${ }^{141}$. Thus, an upcoming research field of xeno-resonance has to be considered, dealing with intrusion and unethical hacking of technologically non-autonomous manipulations in which a two-way resonance is made impossible. Xeno-Resonances can be seen already in remotely controlled direct interference such as in heart pace-

136 Capogrosso et al., 2016.

137 See: Grau et al 2014; Yoo et al., 2013. Since 2013 it is possible to transmit sensory-motorinformations and commands in between animal brains mediated via the internet: See:Pais-Vieira et al., 2013.

138 Trimper et al., 2014.

139 Alpert, 2007.

140 Scheler 1913\{1973\} cit. in: Waldenfels, 2015, 91.

141 In relation to personality alteration Madary and Metzinger $(2016,19)$ propose an informed precaution approach for the use of VR immersive technologies:"VR technology holds the potential to create robust social hallucinations, to directly manipulate the sense of agency, to modulate personality traits via identification with virtual characters, or to causally interact with deeper levels of self-consciousness (UI-manipulation). Users have to be made aware of this possibility". 
makers ${ }^{142}$, which can change the systemic state of an acting and experiencing person, deviating its somatic, mental and social affect relations and personal attunments. Xenoresonance is an important concept to be developed further, if concurrent resonances, different degrees of autonomy, agency and liberty and not only cooperative resonances ${ }^{143}$ are at stake and in need of a fundamental human limit to resonance: a right to negate, exit, refuse or resist ${ }^{144}$ (technically) induced, imposed and undesired social resonances.

Within social resonance, in an enhanced common sense notion of koine aisthesis, it needs two to tango; but there is no common music-making possible where one gets absorbed as a slave to the rhythm, that is not yours.

\section{References}

Alpert, S., 2007, Brain privacy: How can we protect it? American Journal of Bioethics, 7, 70-73.

Aristotle, 1996, On Sleep and Dreams (Classical Texts) introduction and translation David Gallop, Liverpool, Aris \& Phillips.

Aristotle, 2002, Nicomachean Ethics, (Translation, introduction and Commentary by S. Broadie and C. Rowe), Oxford, Oxford University Press.

Aristotle, 1906, De Sensu and De memoria, (Translation with Introduction and Comentary by G. Rose), Cambridge, Cambridge University Press.

Aristotle, 2011, De Anima, (Translated with Introduction and Notes by M. Shiffman), Newbury Port, Focus Publishing.

Arnold, M., 1998, Die Platonische Logik der Harmonie: Versuch der Rekonstruktion eines initiatorischen Handelns. In: Wiener Jahrbuch für Philosophie XXVII/1995, 45-78.

142 Halperin et al., 2008.

143 Cf. Pearce et al., 2016.

144 Cf. Rosa 2016, 750 refers to a "fundamental human right of resistance to resonance" (Grundrecht auf Resonanzverweigerung). 
Aspell J. et al., 2013, Turning body and self inside out: visualized heartbeats alter bodily self-consciousness and tactile perception. Psychol. Sci. 24, 2445-2453.

Bailly, F. and Longo, G., 201 1, Mathematics and the Natural Sciences. The physical singularity of Life. London, Imperial College Press.

Bateson, M., 1979, The epigenesis of conversational interaction: A personal account of research development. In: Before speech: The beginning of human communication, London, Cambridge University Press, 63-77.

Berrios, G., 1982, Tactile hallucinations: conceptual and historical aspects, Journal of Neurology, Neurosurgery, and Psychiatry, 45, 285-293.

Bernieri, F. et al., 1988, Synchrony, pseudo-synchrony, and dissynchrony: Measuring the entrainment process in mother-infant interactions, Journal of Personality and Social Psychology, 54, 243-253.

Bernieri, F. and Rosenthal, R., 1991, Interpersonal coordination: Behavior matching and interactional synchrony, in: Studies in emotion \& social interaction. Fundamentals of nonverbal behavior, New York, NY/ Paris: Cambridge University Press/Editions de la Maison des Sciences de l'Homme, 401-432.

Bigelow, A., and Power, M., 2014, Effects of maternal responsiveness on infant responsiveness and behavior in the still-face task. Infancy, 19, 558-584.

Breyer, T. and Gerner, A., 2017, Resonanz in der Interaktion. Eine philosophische Annäherung anhand zweier Proben. In: Resonanz - Rhythmus - Synchronisierung: Interaktionen in Alltag, Therapie und Kunst, Bielefeld, Transcript, 34-46.

Capogrosso, M. et al., 2016, A brain-spine interface alleviating gait deficits after spinal cord injury in primates, Nature, 539, 284-288.

Cardini, F. et al., 2013, It feels like it's me: interpersonal multisensory stimulation enhances visual remapping of touch from other to self. Journal of Experimental Psychology, Human Perception and Performance, 39 (3), 630-637.

Ceunen, E. et al., 2016, On the Origin of Interoception, Frontiers in Psychology, 7 (743), doi: 10.3389/fpsyg.2016.00743, retrieved: 8.6.2017 
Chladni, F., 1809, Traité d' Acoustique, Courcier, Paris, 1809. (Transl. by Robert T.Beyer, Treatise on Acoustics, Springer, Cham, 2015).

Cirelli, L. et al., 2014, Interpersonal synchrony increases prosocial behavior in infants. Dev. Sci., 17 (6),1003-1011.

Clay, Z. et al., 2015, Functional flexibility in wild bonobo vocal behaviour. PeerJ, 3, el1124.

Clayton, M., 2012, What is entrainment? Definition and applications in musical research, Empir. Musicol. Rev. 7, 49-56.

Clayton, $\mathrm{M}$ et al., 2004, In time with the music: The concept of entrainment and its significance for ethnomusicology. Counter Point, 1, 1-45.

Cohen-Kadosh, R. et al., 2009, Induced Cross-Modal Synaesthetic Experience Without Abnormal Neuronal Connections, Psychological Science, 20 (2), 258-265.

Condon, W. and Sander, L., 1974, Neonate movement is synchronized with adult speech: Interactional participation and language acquisition, Science, 183, 99-101.

Condon, W. and Ogston, W., 1966, Sound film analysis of normal and pathological behavior patterns. J. Nerv. Ment. Dis., 143, 338-457.

Critchley, H., and Harrison, N., 2013, Visceral influences on brain and behavior. Neuron, 77, 624-638.

Dahan A., et al, 2016, Exit from Synchrony in Joint Improvised Motion. PLoS ONE, 11 (10), e0160747. https://doi.org/10.1371/journal. pone.0160747, retrieved: 8.3.2017.

Du Bois, J., 2007, The stance triangle. In: Stancetaking in discourse: Subjectivity, evaluation, interaction, Amsterdam, Benjamins, 139-182.

Du Bois, J., 2014, Towards a dialogic syntax. Cognitive Linguistics, 25 (3), 359-410.

Dunbar, R., 1996, Grooming, Gossip, and the Evolution of Language. Harvard University Press. Cambridge, MA.

Dunbar, R., 1993, Coevolution of neocortical size, group size, and language in humans. Behav. Brain Sci., 16, 681-735.

De Jaegher, H. et al., 2017, Grasping intersubjectivity: an invitation to embody social interaction research, Phenom. Cogn. Sci., 16 (3), 491-523. 
De Jaeger, H., 2009, Social understanding through direct perception? Yes, by interacting. Consciousness and Cognition, 18 (2), 535-542.

Delaherche, E. et al. 2012, Interpersonal Synchrony: A Survey of Evaluation Methods Across Disciplines, IEEE Transactions on Affective Computing, 2012,1-20.

Doffman, M., 2009, Making it groove! Entrainment, participation and discrepancy in the "conversation" of a jazz trio, Lang. Hist., 52, 130-147.

Domes, G. et al., 2007, Oxytocin improves "mind-reading" in humans, Biol. Psychiatry, 61, 731-733.

Earp, B. and Savulescu J., 2017, Love drugs: Why scientists should study the effects of pharmaceuticals on human (romantic) relationships, Technology in Society (2017), doi: 10.1016/j.techsoc.2017.02.001, retrieved: 5.7.2017.

Earp, B. et al., 2012, Natural selection, childrearing, and the ethics of marriage (and divorce): Building a case for the neuroenhancement of human relationships, Philosophy \& Technology, 25 (4), 561-587.

Ewald, J., 1892, Physiologische Untersuchungen über das Endorgan des Nervus octavus, Wiesbaden.

Famm, K. et al, 2013, A jump-start for electroceuticals, Nature, 496, 159-161.

Farroni, T. et al., 2004, Gaze Following in Newborns, Infancy, 5 (1), 39-60.

Fitch, 2006, The biology and evolution of music: A comparative perspective. Cognition, 100 (1), 173-215.

Fitzpatrick, P. et al., 2016, Impairments of Social Motor Synchrony Evident in Autism Spectrum Disorder, Frontiers in Psychology, 7, 1323.

Fletcher, G. et al., 2013, The Science of Intimate Relationships, Chichester, Wiley- Blackwell.

Fuchs, T. and De Jaegher, H., 2009, Enactive Intersubjectivity: Participatory sense-making and mutual incorporation, Phenomenology and the Cognitive Sciences, 8, 465-486. 
Fuchs, T. and Koch, S., 2014, Embodied affectivity: on moving and being moved. Frontiers in Psychology, 5. doi: 10.3389/fpsyg.2014.00508, retrieved 12.2.2017.

Fuchs, T., 2015, Pathologies of Intersubjectivity in Autism and Schizophrenia, Journal of Consciousness Studies, 22 (1-2),191-214.

Gallagher, S. and Hutto, D., 2008, Understanding others through primary interaction and narrative practice. In: The Shared Mind: Perspectives on Intersubjectivity, Amsterdam, John Benjamins, 17-38.

Galloti, M. and Frith, F., 2013, Cognition in the we-mode, Trands in Cognitive Science, 17 (4), 160-164.

Garfinkel, S. et al, 2016, Threat and the Body: How the Heart Supports Fear Processing, Trends Cogn Sci, 20 (1), 34-46.

Garfinkel S. et al., 2015, Knowing your own heart: distinguishing interoceptive accuracy from interoceptive awareness. Biol. Psychol., 104, 65-74.

Geeves, A. et al, 2014 The performative pleasure of imprecision: a diachronic study of entrainment in music performance. Frontiers in Human Neuroscience, 8 (683), 1-15.

Grau, C. et al., 2014, Conscious brain-to-brain communication in humans using non-invasive technologies, PLOS ONE 9 (e105225), doi: 10.1371/journal.pone.0105225, retrieved: 28.3.2016.

Gregoric, P., 2007, Aristotle on the Common Sense, Oxford, Oxford University Press.

Grynberg, D. and Pollatos, O., 2015, “How do I do?" Perceiving one's body shapes empathy, Physiology \& Behavior, 140 (C), 54-60.

Griffiths, D. and Tipper, S., 2012, When far becomes near: Shared environments activate action simulation, Quarterly Journal of Experimental Psychology, 65 (7), 1241-1249.

Gross, C. (1995), Aristotle on the brain, The Neuroscientist, 1 (4), 245-250.

Grunwald, A., 2012, Responsible Nanobiotechnology. Philosophy and Ethics, Boca Raton, Pan Stanford Publishing. 
Gruter, K. et al., 2017, The eardrum moves when the eyes move: A multisensory effect on the mechanics of hearing, http://dx.doi. org/10.1101/156570, accessed: 14.7.2017.

Guastella, A. et al., 2008, Oxytosin increases gaze to eye region of human faces, Biol Psychiatry, 63, 3-5.

Guastella, A., et al., 2008, Oxytosin enhances the encoding of positive social memories in humans, Biol. Psychiatry 64, 256-258.

Halperin, D. et al., 2008, Pacemakers and implantable cardiac defibrillators: Software radio attacks and zero-power defenses. Proceedings of the 2008 IEEE Symposium on Security and Privacy, 129-142.

Heinrich, M. et al., 2004, Selective amnesiac effects of oxytosin on human memory, Physiol Behav, 83, 31-38.

Heinrich M. et al., 2003, Social support and oxytosin interact as cortisol and subjective responses to psychosocial stress, Biol Psychiatry 54, 1389-1398.

Heller-Roazen, D., 2007, The inner touch. Archeaology of a Sensation, New York, Zone books.

Helmholz, H., 1896, Die Lehre von den Tonempfindungen, Braunschweig.

Herbert B. et al., 2012, Interoception across Modalities: On the Relationship between Cardiac Awareness and the Sensitivity for Gastric Functions. PLoS ONE 7 (5), e36646, doi:10.1371/journal.pone.0036646, retrieved: 29.3.2017.

Hobson, P., 2007, We share, Therefore we Think, in: Folk Psychology Re-assessed, Dordrecht, Springer, 41-61.

Hobson, P. et al., 2012, Dialogic Linkage and Resonance in Autism, $J$ Autism Dev Disord, 42, 2718-2728.

Jhang, Y. and Oller, D., 2017, Emergence of functional flexibility in infant vocalisations of the first 3 months, Frontiers in Psychology, 8 (400).

Julien D. et al., 2000, Immediacy behaviours and synchrony in satisfied and dissatisfied couples. Can. J. Behav. Sci.,32, 84-90.

Kandasamy, N. et al., 2016, Interoceptive abilities predicts survival on a London trading floor. Nature Scientific Reports, 6, 32986. 
Killin, A., 2016, Musicality and the evolution of mind, mimesis, and entrainment. Biol Philos , 31, 421-434.

Kirsch, P. et al., 2005, Oxytosin modulates neural circuitry for social cognition and fear in humans, J. Neurosci, 25, 11489-11493.

Kepler, J., 1619, Harmonices Mundi, Gottfried Tamachius Tambach Bibl. Francof.

Kobayashi, H. and Koshima, S., 2001, Unique morphology of the human eye and its adaptive meaning: Comparative Studies on external morphology of the primate eye. Journal of Human Evolution 40, 419-435.

Kosfeld, M. et al., 2005, Oxytosin increases trust in humans, Nature 435, 673-676.

Krueger, H.P., 1999, Zwischen Lachen und Weinen: Zwischen Lachen und Weinen, Bd.1, Das Spektrum menschlicher Phänomene, Reprint 2013, de Gruyter, Berlin.

Lakens, D. and Stel, M., 2011, If they move in sync, they must feel in sync: Movement synchrony leads to attributions of rapport and entitativity, Social Cognition, 29 (1), 1-14.

Lichau, P. et al. 2009, Anregungen. In: Resonanz. Potentiale einer akustischen Figur. München, Fink, 11-32.

Lyapunov, M., 1892, General Problem of the Stability of motion, Mathematical Society Kharkow. London, Taylor \& Francis.

Madary, M. and Metzinger, T., 2016, Real Virtuality: A Code of ethical Conduct. Recommendations for Good Scientific Practice and the Consumers of VR Technology, Frontiers in Robotics and Al, 3 (3), 1-21.

Mazzola, G., 2011 , Musical Creativity. Strategies and Tools in Composition and Improvisation, Berlin/Heidelberg, Springer.

Mazzurega, M. et al., 2011 , Self-other bodily merging in the context of synchronous but arbitrary-related multisensory inputs, Experimental Brain Research, 213 (2-3), 213-221.

Melzoff, A. and Moore, M., 1977, Immitation of Facial and Manual Gestures by Human Neonates, Science, 198, 75-78.

Melzoff, A. et al, 2010, Social Robots are psychological agents for infants: a test for gaze following, Neural Networks 23, 966-972. 
Nancy, J.L., 2002, À l'écoute, Éditions Galilée, (Engl. Trans. Listening, by Charlotte Mandel, New York, Fordham University Press, 2007).

Nancy, J.L., 2008, Forword Ascoltando, in: Szendi, P., Listen. The Story of our Ears. New York: Fordham University Press.

Nelson, A., et al., 2014, Psychological data from an exploration of the rapport / synchrony interplay using motion energy analysis. J. Open Psychol. Data 2 (1), e5: http:// dx.doi.org/10.5334/jopd.ae, retrieved: 23.7.2017

Newton, I., 1687, Philosophiae naturalis principia mathematica, London.

Oller, D., 1980, The emergence of the sounds of speech in infancy, Child Phonology 1, 93-112.

Oller, D. et al., 2013, Functional flexibility of infant vocalizations and the emergence of language, PNAS 110 (16), 6318-6323.

Otabe, T., 2015, The idea of "common sense" revisited: a contribution of an "aesthetic turn" of aesthetics, Serbian Architectual Journal, (=Revisions of Modern Aesthetics, 1), 37-46.

Páez, D. et al., 2015, Psychosocial effects of perceived emotional synchrony in collective gatherings, Journal of Personality and Social Psychology, 108 (5), 711-729.

Paladino, M. et al. 2010, Synchronous sensory stimulation blurrs selfother boundaries. Psychol Sci. 2010, 21 (9), 1202-1207.

Pais-Vieira, M. et al., 2013, A brain-to-brain interface for real-time sharing of sensorimotor information. Scientific Reports, 3, 1319.

Pearce, E. et al, 2016. Singing together or apart: The effect of competitive and cooperative singing on social bonding within and between subgroups of a university Fraternity, Psychology of Music, 44 (6), 1255-1273.

Peters D. (2010). Enactment in listening: intermedial dance in EGM sonic scenarios and the bodily grounding of the listening experience. Perform. Res. , 15 (3). http://egm.kug.ac.at/fileadmin/media/egm/Dokumente/ Peters_preprints/Peters_Enactment_in_Listening_preprint.pdf, retrieved: 3.4.2017. 
Pearce, E. et al., 2016. Tuning in to others: Exploring relational and collective bonding in singing and non-singing groups over time. Psychology of Music, 45 (4), 1-17.

Peca, A. et al., 2016, Robot enhanced Therapy for Children with Autism Disorders. Measuring Ethical Acceptability. IEEE Technology and Society Magazine, June 2016. 54-66.

Plessner, H., 1923, Die Einheit der Sinne, Grundlinien einer Aisthesiologie des Geistes, in: Anthropologie der Sinne, Gesammelte Schriften III, Suhrkamp, Frankfurt, 2003, 7-316.

Porter, J. (2013). Why are there nine muses? In: Synaesthesia and the Ancient Senses. Routledge, London and New York, 9-26.

Porter, J., 2010, The Origins of Aesthetic Thought in Ancient Greece. Matter, Sensation and Experience, Cambridge, Cambridge University Press.

Przyremble, M., 2014, Empathische Egoisten. Eine interdisziplinäre Analyse zur Perspektive der zweiten Person. Freiburg/München, Alber.

Radke, S. and Bruijn, E., 2015, Does oxytocin affect mind-reading? A replication study, Psychoneuroendocrinology (2015), http://dx.doi. org/10.1016/j.psyneuen.2015.06.006, retrieved: 15.7.2017.

Ramseyer F., Tschacher W., 2011 , Nonverbal synchrony in psychotherapy: coordinated body movement reflects relationship quality and outcome, J. Consult. Clin. Psychol. 79, 284-295.

Ratcliffe, M., 2007, From Folk Psychology to Common Sense. In: Folk Psychology Re-Assessed, Dordrecht, Springer, 223-243.

Ratcliffe, M., 2013, Why Mood Matters, in, Cambridge Companion to Being and Time, Cambridge, Cambridge University Press, 157-176.

Ratcliffe, M., 2008, Existential Feelings of Being, Oxford, Oxford University Press.

Ratcliffe, M., 2015, Experiences of Depression, A study in phenomenology, Oxford, Oxford University Press.

Reddish, P., et al., 2013, Let's dance together. Synchrony, Shared Intentionality and Cooperation, PLOS ONE 8 (8): e71182.http://doi. org/10.1371/jornal.pone.0071182, retrieved: 5.6.2017. 
Rennung, M. and Göritz, A., 2016, Prosocial Consequences of Interpersonal Synchrony. A Meta-analysis. Z. Pszchol., 224 (3), 168-189.

Rosa, H., 2016, Resonanz. Eine Soziologie der Weltbeziehung, Berlin, Suhrkamp.

Savalescu, J. Sandberg, A. 2008, Neuroenhancement of Love and Marriage. The Chemicals between us, Neuroethics 1, 31-44.

Schandry, R, 1981, Heartbeat perception and emotional experience. Psychophysiology, 18, 483-488.

Schilbach, L., 2010, A second-person approach to other minds, Nature Reviews Neuroscience, 11 (6), 449.

Schirmer-Mokwa, K. et al., 2015, Evidence for Enhanced Interoceptive Accuracy in Professional Musicians. Frontiers in Behavioral Neuroscience, 9, 349.

Seeman, A. 2011 , Joint Attention. New Developments in Psychology, Philosophy of Mind, Social Neuroscience, MIT Press, Cambridge.

Stern, D., 1971, A micro-analysis of mother-infant interaction: Behaviors regulating social contact between mother and her three-and-a-monthold twins. Jornal of the American Academy of Child Psychiatry, 10, 501-517.

Stern, D., 1974, Mother and infant at play: the dyadic interaction involving facial, vocal, and gaze behaviors", in The Effect of the Infant on Its Caregiver, New York, NY, Wiley, 187-213.

Stern, D., 1985, The Interpersonal World of the Infant, New York, Basic Books.

Suzuki, K. et al. 2013, Multisensory integration across exteroceptive and interoceptive domains modulates self-experience in the rubber-hand illusion. Neuropsychologia 51, 2909-2917.

Sheets-Johnstone, M., 2011 , The Primacy of movement, expanded second edition, John Benjamins, Amsterdam.

Schilbach, L. et al., 2013, Towards a second-person neuroscience, Behavioral and Brain Sciences, 36 (4), 393-414.

Schütz, A., 1976, Making music together. A study in social relationships, Collected Papers II, Studies in Social Theory, (=Phänomenologica; 
ed. and introd. By Arvid Broderson, reprint from 1951, Martinus Nijhoff: The Hague, 159-178.

Schütz, A., 1976b, Mozart and the Philosophers, Collected Papers II, Studies in Social Theory, (=Phänomenologica; ed. and introd. By Arvid Broderson, reprint from 1951, Martinus Nijhoff: The Hague, 179-200.

Stanghellini, Giovanni, 2004, Disembodied spirits and deanimated bodies. The psychopathology of common sense, Oxford, New York, Oxford University Press.

Tomasello, M, 2014, A Natural History of Human Thinking, Cambridge/ London, Harvard University Press.

Tomasello, M. et al., 2005, Understanding and sharing Intentions: the origins of cultural cognition, Behavioral and Brain Sciences, 28, 675-691.

Tomasello, M. et al., 2007, Reliance of Head versus Eye in the gaze following of great apes and human infants: The cooperative eye hypothesis, Journal of Human Evolution, 52, 314-320.

Trevarthen, C., 1979, Communication and Coorporation in early infancy. A description of primary intersubjectivity. In: Before Speech: The Beginning of Human Communication. London: Cambridge University, 321-347.

Trevarthen, C., 2001, Infant intersubjectivity: research, theory, and clinical applications. J. Child Psychol. Psychiatry 42, 3-48.

Trevarthen, C., 2009, Human biochronology: On the source and function of "musicality". In: Music that works: Contributions of Biology, Neurophysiology, Psychology, Sociology, Medicine and Musicology, Wien, Springer, 221-265.

Trevarthen, C., 2011 , The Generation of Human Meaning. How Shared Experience Grows in Infancy, In: Joint Attention. New Developments in Psychology, Philosophy of Mind, and Social Neuroscience, 73-113.

Trevarthen, C. et al. $2011 \mathrm{~b}$, Psychobiology of musical gesture: Innate rhythm, harmony and melody in movements in narration, in: New perspectives on music and gesture, Aldershot, Ashgate, 11-43.

Trevarthen, C., 1979, Communication and Coorporation in early infancy. A description of primary intersubjectivity, in: Before Speech: The Beginning of Human Communication, London, Cambridge University Press, 321-347. 
Trevarthen, C. et al., 2006, Collaborative regulations of vitality in early childhood: Stress in intimate relationships and postnatal psychopathology, Developmental psychopathology, Vol.2 Developmental neuroscience, New York: Wiley, 65-126.

Trimper, J. et al., 2014, When "l" becomes "We": ethical implications of emerging brain-to-brain interfacing technologies, Front. Neuroeng. 7 (4). doi: 10.3389/fneng.2014.00004.

Tschacher, W. et al., 2014, Nonverbal synchrony and affect in dyadic interactions, in: Frontiers in Psychology 5, 1323.

van Baaren, R. et al, 2004, Mimicry and Prosocial Behavior. Psychological Science, 15 (1), 71-74.

Varlet, M., et al., 2012, Impairments of social motor coordination in schizophrenia. PLOS ONE, 7:e2977210.1371/journal.pone.0029772 retrieved: 2.7.2017.

Yoo, S., 2013, Non-invasive brain-to-brain interface (BBI): establishing functional links between two brains, PLOS ONE 8 (e60410), doi: 10.1371/ journal.pone.0060410, retrieved: 5.5.2016.

Young, L, Alexander, B., 2012, The Chemistry between us. Love, Sex and the Science of Attraction, London, Pinguin.

Waldenfels, B., 2010, Sinne und Künste im Wechselspiel. Modi ästethischer Erfahrung, (=stb 1973) Frankfurt, Suhrkamp.

Waldenfels, B. 2015, Sozialität und Alterität. Modi sozialer Erfahrung, Suhrkamp, Berlin.

Wardhaugh, B., 2008, Formal Causes and Mechanical Causes: The Analogy of the musical Instrument in the late seventeenth-century natural philosophy. In: Philosophies of Technology. Francis Bacon and his contemporaries. (=Intersections, Vol.11), Leiden/Bosten, Brill, 411-428.

Wasserman, D. and Liao S, 2008, Issues in the Pharmacological Induction of Emotions, Journal of Applied Philosophy, 25 (3), 178-192.

Weber, E., 1846, Der Tastsinn und das Gemeingefühl, in: Handwörterbuch der Physiologie mit Rücksicht auf physiologische Pathologie. Band 3. Teil 2, Braunschweig, Vieweg, 481-588. 
Welsh, C., 2009, Resonanz-Mitleid-Stimmung: Grenzen und Transformation des Resonanzmodells im 18. Jahrhunderts, in: Resonanz. Potentiale einer akkustischen Figur, München, Fink, 103-122.

Wiltermuth, Scott, 2012, Synchrony and destructive obedience. Social Influence, 7, 1-12.

Wiseman, H., 2015, The Myth of the Moral brain. The Limits of Moral Enhancement, Cambridge, MIT Press.

Wolf, W. et al., 2016, Joint attention, shared goals, and social bonding. Br.J. Psychol., 107 (2), 322-327.

Wudarczyk, O. et al., 2013, Could intranasal oxytocin be used to enhance relationships? Research imperatives, clinical policy, and ethical considerations, Current Opinion in Psychiatry, 26 (5), 474-484. 